\section{Una obra en Valparaíso}

Miguel Eyquem Profesor, Escuela de Arquitectura, Universidad Católica de Valparaíso

Mirando Valparaíso desde una perspectiva reflexiva, se hace hincapié en las diferentes lecturas que se pueden tener de una misma obra. La relación de la obra con el tejido urbano y con el legado patrimonial, y su buena factura están presentes en el relato.
Looking at Valparaiso through reflection, emphasis is placed on the different ways in which one same work can be read. The relationship of the work to the urban weave and the heritage as well as the good style of the work are present in the narrative.

Lofts Yungay, Valparaíso. Antonio Menéndez, Cristián Barrientos / Los autores emprenden una operación inmobiliaria por su propia iniciativa. Por tanto les pertenece la decisión del lugar. Un lugar central dentro del anfiteatro: la calle General Mackenna, que baja a un encuentro con un eje central muy importante y dinámico. Desde el mar: Bellavista, Plaza Ecuador, Cementerio, Av. Alemania, un valle transversal. De tal manera esa calle, General Mackenna, queda referida directamente al mar, es decir, al destino de Valparaíso.

En este proyecto los autores proponen un criterio para interpretar el carácter patrimonial, aunque el lugar esté fuera del área protegida. Este criterio de conservar el estilo porteño en él, frente a la calle, la conservación del espíritu arquitectónico. Semejante criterio se ha aplicado, como todos sabemos, en ciudades europeas para mantener el carácter, el aspecto mismo de los viejos barrios históricos. Va dirigido especialmente en interés del turismo: conservar el espacio público. Los interiores pueden ser transformados, reconstruidos modernos, habitables.

Se trata de un edificio nuevo, de hormigón revestido con zinc y vidrio. Un frente, entonces, que no rompe la continuidad de la calle, bien construido, con detalles estudiados, elementos de calidad, con sus calaminas finas de un azul luminoso y ventanas clásicas, verticales $1 \mathrm{x} 2 \mathrm{~m}$ con marcos de madera barnizada y bisagras, picaportes de bronce: un lujo. Un zócalo moderno, blanco con bloques de vidrio. Aquí aparece un pequeño porche que cobija al visitante frente a una puerta de reja metálica diseñada con sensibilidad visual y táctil, con perfiles especiales. Así se ofrece toda la vista de un patio lleno de luz, iluminado por el mismo azul de la fachada, por paños verticales de calamina azul entre franjas importantes de vidrio, $1.60 \mathrm{~m}$ entre 
barras horizontales. Cuatro lados equivalentes. Estas franjas de toda la altura (dos niveles). Esa propiedad del vidrio de transparencia, reflejo, luz y oscuridad siguiendo la vista del observador, proporciona una vida y especialidad enriquecidas: el pequeño patio, alegre, con mucho verde, aumentado por los halles de acceso de doble altura a través de los vidrios transparentes. Un patio acogedor por su buena factura, cuidada.

Accediendo a un departamento de inmediato se aprecia el delicado trabajo de ajuste para dar cabida al programa propuesto, cuando los límites del espacio dado son exigentes: ni un centímetro más entre medianeras. Nos encontramos con nuestros cuerpos ajustados con dimensiones muy precisas. Más allá de lo propuesto este ha sido un problema de nuestro tiempo. Los europeos al principio del s. XX enfrentaron esta concepción en la industria: las medidas mínimas ajustadas al cuerpo. Ya El Modulor propuso dos escalas de dimensiones para ajustarse a distintos estándares. Fabricaron los vehículos más pequeños posibles: el Fiat Balilla, el Topolino. Los ingleses con el Austin Mini, más moderno, propusieron una invención muy original: cómo lograr a través del diseño, que al introducirnos en un pequeño volumen, este se transforma en amplio, espacioso.

Los autores han propuesto un programa para gente joven que requieren pocos metros para comenzar y Valparaíso no los ofrece. En las ciudades modernas se genera el fenómeno de la migración, entre casas, entre barrios. Hay un flujo permanente. Esta obra propone una habitación transitoria. (Arquitectura: dentro de los límites ajustados, las medidas deben ser muy precisas, una concepción de lo mínimo arquitectónico, con real diseño)

Uno de los departamentos de atrás, con frente a la quebrada. Se

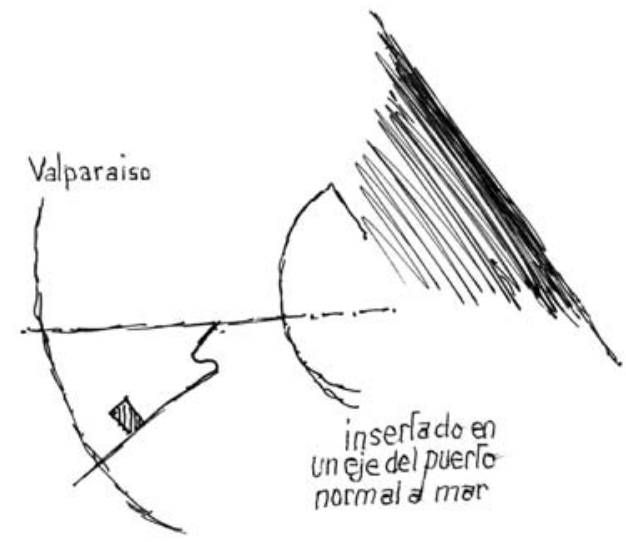

accede bajando con un giro por una caja escala muy iluminada por el patio; se llega transversalmente al living-cocina bien armado para su tamaño. Su ventana balcón se abre al valle de la Av. Ecuador, una bajada a un jardín propio. Volviéndose hacia el fondo del living, dividiendo la zona de estar, un dintel amarillo, un toque de iluminación. El espacio sigue más allá del dintel de la cocina, un mesón con baranda atrás; esta es la baranda de la escalera de acceso iluminando el fondo con su caja: luz cenital del patio azul.

Hacia el lado izquierdo, bajo el dintel, el muro se curva hacia los dormitorios. Aquí se percibe que este espacio ajustado posee, sin embargo, unas fugas que profundizan. El muro tras la curva da acceso a un vano oscuro, interior. Al fondo del lado izquierdo, en la esquina, otro vano oscuro y en la esquina derecha, la claridad que baja con la escalera que viene desde el patio. La escalera dibuja los escalones en negro, los que continúan bajando la pared del fondo apoyándose en una baranda de madera, una diagonal fuerte que cruza de la luz a la sombra. Un espacio enriquecido con detalles arquitectónicos.

En los pequeños departamentos de tres niveles (terraza) el acceso es desde el patio, abriendo la puerta en el paño de vidrio de toda la altura del edificio, se accede a un espacio de doble altura: prolongación del patio con toda su luz. Un hall luminoso, amplio, donde se presenta desprendida y centrada una escalera de caracol metálica: elementos delgados para permitir la transparencia luminosa. La gran caja-escalera-hall de entrada ilumina todos los niveles. Arriba, algunos son bien logrados por su doble orientación: patio y calle. Por último, la terraza es como asomarse a la cubierta de un barco, protegida dentro de una jaula de madera. Un volumen ligero para rematar el edificio. ARQ 